\title{
Face-to-face Training as an Effective Approach for Instructing Rotahaler Technique in Newly Diagnosed Cases of Asthma and COPD: a Pilot Study
}

\author{
Ramesh Sharma Poudel,' Shakti Shrestha, ${ }^{2}$ Rano Mal Piryani,, ${ }^{3}$ Aastha Prajapati,' Dipendra Khatiwada ${ }^{4}$ \\ 'Hospital Pharmacy, Chitwan Medical College Teaching Hospital, Chitwan, Nepal, '²Department of Pharmacy, Shree Medical \\ and Technical College, Chitwan, Nepal, ${ }^{3}$ Department of Internal Medicine, Chitwan Medical College Teaching Hospital, Chitwan, \\ Nepal, ${ }^{4}$ Department of Community Medicine, College of Medical Sciences Teaching Hospital, Chitwan, Nepal.
}

\section{ABSTRACT}

Introduction: This study aimed to evaluate the effectiveness of face-to-face training for instructing rotahaler technique in newly diagnosed cases of asthma and chronic obstructive pulmonary disease (COPD).

Methods: A hospital-based study was conducted on twenty patients who were prescribed rotahaler for the first time. Patients received face-to-face training on rotahaler technique from pharmacist using GINA guidelines. The patients rotahaler technique was assessed after two weeks of training and scored one for correct and zero for incorrect steps. Descriptive statistics was performed.

Results: The mean age of the study population was $48.85 \pm 20.49$ years. Eleven (55\%) patients were females and $13(65 \%)$ were formally uneducated. Fourteen patients $(70 \%)$ were able to perform all the steps correctly giving overall median score of 8 (7-8).

Conclusions: Face-to-face training seems to be effective approach for instructing rotahaler technique in asthma and COPD patients.

Keywords: asthma; COPD; face-to-face training; inhaler technique; pharmacist.

\section{INTRODUCTION}

Inhaled medications are the keystone for the treatment of obstructive lung diseases ${ }^{1,2}$ and pressurized metered dose inhalers (pMDIs) and dry powder inhalers (DPIs) are the devices mostly used for delivering the medications to the lungs. However, large majority of the patients were unable to use their dry powder inhalers correctly ${ }^{3}$ that results in reduced therapeutic effect. ${ }^{4}$ The quality of initial instruction is a foundation for the outcomes of inhalation therapy. ${ }^{5}$ A study by Shrestha et al demonstrated that combination of video and demonstration was useful tool for improving rotahaler technique. ${ }^{6}$ Improvement of inhalation technique not only reduces the frequencies of total as well as nocturnal asthma symptoms but also reduces the frequencies of beta- 2 agonist usage. ${ }^{4}$

In Nepal, most of the patients receive only verbal instruction but the effectiveness of face-to- face training approach for instructing rotahaler technique by healthcare professionals in newly diagnosed patients of asthma and chronic obstructive pulmonary disease has not been explored. Our study may be the first in such setting in Nepal to evaluate the effectiveness of face-to-face training approach for instructing rotahaler technique in newly diagnosed case of asthma and chronic obstructive pulmonary disease.

\section{METHODS}

This study was conducted at the outpatient pharmacy of Chitwan Medical College Teaching Hospital from November 2014 to February 2015. Twenty newly diagnosed cases of asthma and COPD who were been prescribed rotahaler device for the first time were

Correspondence: Ramesh Sharma Poudel, Hospital Pharmacy, Chitwan Medical College Teaching Hospital, Bharatpur-10, Chitwan, Nepal. Email: pharmacistsharma23@gmail.com, Phone: +977-9843089582. 
selected. Socio-demographic information was obtained and rotahaler technique was instructed through face-toface training using GINA guidelines (rotahaler specific checklist) ${ }^{7}$ by a registered pharmacist. After two weeks of training, the pharmacist assessed the technique using the same rotahaler specific checklist. Each correct step was scored 'one' and incorrect or missed step was scored 'zero'. Descriptive statistics was performed using SPSS version 20.

\section{RESULTS}

The mean age of the study population was $48.85 \pm 20.49$ years. Eleven $(55 \%)$ patients were females. Thirteen patients $(65 \%)$ were formally uneducated and fifteen patients $(75 \%)$ living in rural areas (Table1).

\begin{tabular}{|lll|}
\hline \multicolumn{2}{|l|}{$\begin{array}{l}\text { Table 1. Socio-demographic characteristics of study } \\
\text { population. }\end{array}$} \\
\hline \multicolumn{2}{|l}{ Sociodemographic characteristics } & $\mathbf{n}(\%)$ \\
Age in years (mean \pm SD) & $48.85 \pm 20.49$ \\
Gender & Male & $9(45 \%)$ \\
& Female & $11(55 \%)$ \\
& Formally uneducated & $13(65 \%)$ \\
\multirow{4}{*}{ Education } & Primary education & $1(5 \%)$ \\
& Secondary education & $5(25 \%)$ \\
\multirow{2}{*}{$\begin{array}{l}\text { Residential } \\
\text { area }\end{array}$} & Intermediate level & $1(5 \%)$ \\
\cline { 2 - 3 } & Rural & $15(75 \%)$ \\
\hline
\end{tabular}

\begin{tabular}{|c|c|}
\hline $\begin{array}{l}\text { Table 2. Frequency of correct rotaha } \\
\text { performance. }\end{array}$ & ch \\
\hline Rotahaler Checklist & n (\%) \\
\hline Step 1: Hold rotahaler vertically & $20(100)$ \\
\hline Step 2: Put capsule into square hole & $20(100)$ \\
\hline Step 3: Splits capsule into cap and body & $20(100)$ \\
\hline Step 4: Breathe out gently & $15(75)$ \\
\hline $\begin{array}{l}\text { Step 5: Put mouthpiece between lips and } \\
\text { teeth }\end{array}$ & $20(100)$ \\
\hline $\begin{array}{l}\text { Step 6: Breathe in the powder quickly and } \\
\text { deeply }\end{array}$ & $20(100)$ \\
\hline Step 7: Take inhaler out of mouth & $20(100)$ \\
\hline Step 8: Hold breath for about 10 seconds & $16(80)$ \\
\hline 6 & $3(15)$ \\
\hline Scores & $3(15)$ \\
\hline 8 & $14(70)$ \\
\hline
\end{tabular}

Fourteen patients $(70 \%)$ were able to perform all the steps correctly. The overall median (IQR) score was 8 (7-8). Five patients (25\%) failed to 'breathe out gently' before inhalation and four patients $(20 \%)$ failed to 'hold breath for about ten seconds' after inhalation (Table2).

\section{DISCUSSION}

Incorrect use of inhaler technique is a common problem worldwide. In our pilot study, we analyzed the effectiveness of face-to-face training approach for instructing rotahaler technique. In this study, fourteen patients $(70 \%)$ were able to perform all the steps correctly after the training, giving an overall median (IQR) score of 8 (7-8). A study by Shrestha et al in Kathamandu demonstrated that before intervention, only $42.2 \%$ of the patients used their inhaler device correctly, and most of the patients overestimated their rotahaler technique despite the incorrect inhaler technique, while $61.1 \%$ had never received any previous instruction on the correct use of rotahaler. ${ }^{6}$ Similarly, study done by Graham claimed that $30 \%$ of patients had never been demonstrated the correct use of inhaler. ${ }^{8}$ These results suggests that proper training in inhaler technique is lacking in Nepal. Studies have shown that training can lead to more accurate use of dry powder inhalers. ${ }^{9,10}$ Our study, which was led by pharmacist, also suggested that the correct use of rotahaler technique through face-to-face training was nearly $30 \%$ better than the percentage depicted by Shrestha et al. A Pharmacist-led intervention study to improve inhalation technique in asthma and COPD patients demonstrated that patients who had never received training in correct inhalation technique made more errors in performing inhalation at baseline than those who have had one or more instruction sessions. ${ }^{11}$ The patients included in our study were the newly diagnosed cases of asthma and COPD who received the instruction for the first time. Moreover, a study by Cochrane et al showed that patient's education on disease and technique not only improved inhalation techniques but also improved patients compliance to the therapy and lung deposition of drugs. ${ }^{2}$ The incorrect use of the rotahaler device might be a result of inadequate quality and duration of instruction, and inability of reinforcement by lack of follow-up checks up. ${ }^{3}$ However, we did not reinforce the technique, which could be useful to further improve the correct use of the rotahaler technique from what we have achieved.

In our study, even after training some patient failed to breath out gently before inhalation and hold breath for about ten second after inhalation. Other studies have also mentioned that these are the most common errors while using dry powder inhalers. ${ }^{3,6}$ This emphasize that the reinforcement should focus more on these steps. Furthermore, to ensure that the instructions are correctly provided to patients regarding rotahaler technique, the healthcare professionals should be well educated, trained on rotahaler technique and should have access to demonstration devices. Such approach also improves error detection capability of healthcare professionals. ${ }^{4}$

\section{CONCLUSIONS}

Face-to-face training seems to be effective approach for instructing the rotahaler technique in patients with asthma and COPD. However, a larger scale study is necessary, together with regular assessment and reinforcement. 


\section{REFERENCES}

1. Crompton G. A brief history of inhaled asthma therapy over the last fifty years Prim Care Respir J. 2006;15(6):326-31.

2. Cochrane MG, Bala MV, Downs KE, Mauskopf J, BenJoseph RH. Inhaled corticosteroids for asthma therapy. Patient compliance, devices and inhalation technique. Chest. 2000;117(2):542-50.

3. Lavorini F, Magnan A, Dubus JC, Voshaar T, Corbetta L, Broeders $\mathrm{M}$, et al. Effect of incorrect use of dry powder inhalers on management of patients with asthma and COPD. Respir Med. 2008;102(4):593-604.

4. Molimard M, Raherison C, Lignot S, Depont F, Abouelfath A, Moore N. Assessment of handling of inhaler devices in real life: an observational study in 3811 patients in primary care. J Aerosol Med. 2003;16(3):249-54.

5. Self TH, Brooks JB, Lieberman P, Ryan MR. The value of demonstration and role of the pharmacist in teaching the correct use of pressurized bronchodilators. Can Med Assoc J. 1983;128(2):129-31.

6. Shrestha S, Sapkota B, Ghimirey A, Shakya R. Impact of counselling in inhalation technique (rotahaler) in chronic obstructive pulmonary disease patients. Int J Pharm. 2013; 3(3):442-9.
7. Global Initiative for Asthma (GINA) [. Instruction for inhaler and Spacer use [online]. (Cited 2014 Oct 7). Available at: http:/ / www.ginasthma.org/local/uploads/content/files/ inhaler_charts_2011.pdf.

8. Graham LE. The Ineffective Use of Inhalers in Chronic Obstructive Pulmonary Disease. J Inst Med. 2001;23:22-4.

9. Broeders ME, Molema J, Hop WC, Folgering HT. Inhalation profiles in asthmatics and COPD patients: reproducibility and effect of instruction. J Aerosol Med. 2003;16(2):131-41.

10. Giner J, Macian V, Hernandez C; Grupo EDEN. Multicenter prospective study of respiratory patient education and instruction in the use of inhalers (EDEN Study). Arch Bronconeumol. 2002;38(7):300-5.

11. Hammerlein A, Muller U, Schulz M. Pharmacist-led intervention study to improve inhalation technique in asthma and COPD patients. J Eval Clin Pract. 2011;17(1):61-70. 


\section{Journal of Nepal Medical Association}

\section{INTRODUCTION}

The Journal of Nepal Medical Association (JNMA) is an internationally peer reviewed, PubMed indexed, open access, quarterly biomedical journal published by Nepal Medical Association. It is the first and oldest general meical journal since 1963.

The JNMA works under the belief that knowledge gained through scientific research and scientific advances should be shared and made universally accessible. Hence, it grants readers permission to read, download, copy, distribute, print, search and create links to the full text articles available online at www.jnma.com.np without any charge. Thereby, it also aims to increase the visibility and ease of use of open access scientific and scholarly articles so as to promote their increased usage and impact.

It publishes research based articles from the field of biomedical sciences including basic sciences and clinical disciplines, public health, health care management, ethical and social issues pertaining to health care. Preference is given to clinically oriented applied research, trials over animal studies.

Articles are published under the following categories: Original Article, Review Article, Case Report, Short Communication, Perspectives. The Editorial, Guest Editorial and Letter to the Editor are solicited by the editorial board.

Authors do not have to pay for submission, processing or publication of articles in JNMA.

\section{THE EDITORIAL PROCESS}

The submitted manuscripts are duly acknowledged and initially reviewed for possible publication by the Editors with the understanding that they are being submitted only to the JNMA, have not been published, simultaneously submitted or accepted for publication elsewhere. On an average, 30-40\% of the manuscripts with insufficient originality or significant message, serious scientific and technical flaws are rejected. In case of a good article that has been written poorly, the authors are asked to resubmit after revision.

The manuscripts are then sent to two expert peer reviewers blinded to the contributor's identity and vice versa for meticulous review, inputs and comments. The final decision on whether to accept or reject the article are taken by the editorial board based on the peer reviewer's comments. The contributor's are informed about the rejection/acceptance of the manuscript with the peer reviewer's comments. Accepted articles have to be resubmitted after making the necessary changes or clarifying questions made during the peer review process.

The accepted articles are edited for grammatical, punctuation, print style and format errors and page proofs and are sent to the corresponding author who should return them within three days. Non response to galley proof may result in delay in publication or even rejection of the article.

\section{INSTRUCTIONS TO AUTHORS}

Manuscripts must be prepared in accordance with "Uniform requirements for Manuscripts submitted to Biomedical Journals" developed by the International Committee of Medical Journal Editors. The uniform requirements and specific requirement of JNMA are summarized in our website www.jnma.com.np

We request our author to check JNMA author guidelines each time they submit manuscript to us.

\section{MANUSCRIPT SUBMISSION}

Manuscripts must be submitted in clear, concise English. Please submit a mandatory electronic copy of supplemenatry files along with your manuscript to our online submission system. These supplemanry files are: Forwarding, Authorship (signed by all authors) and Declaration letters (samples are available in the JNMA website).

For, official purpose, please contact;

Dr. Angel Magar

Editor-in-Chief

Journal of Nepal Medical Association,

NMA Building, Siddhi Sadan, P.O. Box 189

Exhibition Road, Kathmandu, Nepal.

Email: editor@jnma.com.np

Web: www.jnma.com.np

\section{MANUSCRIPT PREPARATION}

All manuscripts should adhere to the JNMA format. The manuscript must be typed double-spaced on one side of an A4 size white paper with Arial Font (size 12). A minimum of $25 \mathrm{~mm}$ margins should be present. 